\title{
The (Long) Nose Doesn't Have It: Nose Length as a Factor in Salt and Pepper Passage
}

\author{
Pat Minér \\ Université Collège du Québec, \\ Québec, Canada
}

\author{
Bill Horn \\ University Institute of Ontario at \\ Wawa, Ontario, Canada
}

\author{
Minér Patrick \\ Collège Catholique du Roussilon \\ Anglais Privée, Roussilon, la France
}

\begin{abstract}
In extension of previous works, eighty female undergraduates complete questionnaire with snacks and drinks, along with a salt shaker and a pepper shaker available. They are asked to pass salt or pepper by another female or a male who also works on questionnaire, but who is in league with the experimenter. These confederates have either the very long nose or normal-sized (short) nose (le nez normal). Participants comply to both requests, but are slower to respond to pepper request than to salt request and to the person with the long nose. Response times are particularly slow when the request was made by male with long nose (homme avec le nez long). Implications for similarity theory and attraction theory are discussed and suggestions are made for the future research going forward.
\end{abstract}

Keywords: nose length, salt passage, pepper passage

Pencil (1976) writes that what appears to be simple request to pass the salt has actually been the subject of consideration for literary writers and even philosophers in the English tradition. However, there are reports of psychological research conducted to test various ideas in the manner empirical. Two literature reviews (Pacanowsky, 1978; Pencil, 1976) identified a number of determinants of the salt passing: politeness of request to pass salt, number of people present, and both attitudes and race of sender and receiver. The writers recommend more research, particularly on various personal characteristics. Answering this call many years later, Minér (2015) recently proposed that salt passage was related to both sex of recipient and sex of sender, with faster response times when the request was made by a member of the opposite sex. It was speculated that this result might be mediated by physical attractiveness. If true, attractiveness theory would trump similarity theory according to which the response would be faster to a member of same sex.

Purpose of present proposed experiment was to extend this discussion by incorporating attractiveness directly into the equation. Because natural physical attractiveness cannot be examined experimentally, it was approached by artificially manipulating a facial feature that has been related to attractiveness: the nose (Seriously Science, 2014) and, more specifically, nose length (Baudouin \& Tiberghien, 2004; McKelvie, 1993). This feature was also chosen because there were local facilities to create noses to prescription (see Method). In addition, and in the spirit of complete transparency, two of the researchers themselves (BH, LLN) each have been blessed (or cursed) with a large "Gallic" or Roman nose (although not as long as the artificial one used

Pat Minér, Professeur Principal Adjoint, école des Sciences Sociales et Communications, Université Collège du Québec. Bill Horn, School of Physiognomy, University Institute of Ontario at Wawa.

Minér Patrick, Professeur Sou-Principal Ajoint, école des Sciences Psychologiques Sociales, Collège Catholique du Roussilon Anglais Privée. 
here), and were somewhat "nosy" about the effects of this manipulation. In contrast, two of the researcher (PM and MP) have extremely flat noses. These personal factors prompted interest in present topic.

Research shows that people with longer noses are perceived as less attractive than people with shorter noses (Beaudion \& Tiberghien, 2004; McKelvie, 1993). Because compliance is less likely when requester is less attractive (Debevec, Mardin, \& Kernan, 1986), it was predicted that participants would be less likely to pass the salt to person with long nose compared to person with short (normal) nose. Although all participants were female, person making the request to pass salt or pepper was either male or female. Sex of requester was not expected to be a factor on the effect of nose length, but it provided another test of attractiveness theory, according to which the female participants would respond faster to a male than to a female.

The second purpose of present research was to extend investigation from passage of salt to passage of pepper. This question has been considered by Minér (2015), who suggested that response time was slower for passing pepper than for passing salt. Thus, it was predicted that response time would be slower for pepper passage than for salt passage. However, it was not clear whether this pattern would be affected by nose length. Given that pepper can cause sneezing, it was speculated that the request for pepper made by person with long nose may be special. Consciously or unconsciously, the participant might associate the pepper and the nose with sneezing (and may even be instigated to sneeze), creating a distraction from task at hand. Consequently, the slowest times might occur when the person with the long nose asks for pepper to be passed.

\section{Method}

\section{Participants}

Eighty female undergraduates are recruited from introductory psychology courses at three institutions (25 to 27 from each) and were given 2 credit points towards their final grade. They were assigned at random to four requester conditions $(n=20)$ : male with long nose, male with short (normal) nose, female with long nose, and female with short (normal) nose.

\section{Materials}

Materials consist of salt shaker, pepper shaker, and questionnaire about music preferences. Details of questionnaire are not included here because these datas are not analyzed. Questionnaire is only given to conceal real purpose of experiment. Most importantly, for proposed experiment, a lifelike long false nose was constructed in department of fine arts at the university institution and, with assistance from makeup experts in department of drama, male and female confederates were fitted with long noses for long nose condition. A brief pre-test check indicates that long noses blended well with faces and that these noses were indeed perceived as abnormally long. In short nose condition, the assistants simply display own natural noises, and the observers indicated that they were perceived as normal in length.

\section{Procedure}

Participants sign up for a study of music preferences, being tested individually in psychology laboratories. On arrival, experimenter explains that they and another participant would sit opposite each other at a table and complete questionnaire. Filling it out will take approximately 20 minutes. Other person is also undergraduate, but confederate of (in league with) experimenter. He/she always makes the request and true participants (who were asked to pass salt or pepper) are always senders. Salt and pepper shakers are closer to sender's side of table. To ensure this, there is the draw for which side of the table the two people would sit, but it is rigged so 
that sender would always be in appropriate location.

Participants complete questionnaire at own speed. They are also given two bowls, one filled with unsalted peanuts and one filled with unsalted potato chips, and a choice of water, orange juice and cranberry juice to drink. It is made clear that participants could snack and drink as they wished.

The confederates are two students, one male and one female from same institution as participant. Each one serves in long nose condition and in short nose condition. Thus, as stated above, participants are divided into four separate groups: male long-nosed requester, male short-nosed requester, female long-nosed requester, and female short-nosed requester. The confederates complete questionnaire like real participant, and they ask the participant to pass salt or the pepper according to following schedule: first request after five minutes and second one after one more minute. For half of the participants, first request is for salt to be passed and second for pepper to be passed, and for the other half the requests are counterbalanced in opposite order. The first and second requests are delivered respectively as follows: "Excuse me, would you pass the salt (pepper)?" and "Sorry to bother you again, but would you pass the pepper (salt)?" If request is honoured, recipient returns the salt or pepper shaker to its original spot.

Behavior of sender (whether or not he or she actually passed salt or pepper) is independently observed by two observers through one-way mirror. They are blind as to the purpose of experiment. In addition, using stopwatches, they also independently record time from when request was made until sender lift shaker. Finally, at end of experiment, they also independently rate nose size of participants on a scale from 1 to 9 where 1 was "Extremely short", 2 was "Very short", 3 was "Short", 4 was "Slightly short", 5 "Neutral", 6 was "Slightly long", 7 was "Long", 8 was "Very long" and 10 was "Extremely long". To give benchmark to ratings, "Extremely long" is defined as length of artificial long nose. These ratings are obtained at the end so that they would not contaminate estimates of response times.

It should also be noted that experimenters also observe proceedings through another one-way mirror. However, they do not keep any records in systematic manner.

\section{Results}

Datas were entered as expected according to hypotheses and analyzed using SPSS (PASW Statistics 18), with alpha set at 0.05 .

\section{Nose Length of Participants}

Ratings of nose lengths by the two observers are close to each other (never more than one rating point apart). The datas for analysis consisted of mean of the two ratings for each participant.

Over all participants, mean length of their noses was rated as $5.1(S D=0.5)$. Indeed, $85 \%$ of the ratings were 5 (neutral) and the others were 4 (slightly short) or 6 (slightly long). Moreover, A $2 \times 2$ (Sex of Recipient $\times$ Nose Length) between groups ANOVA on ratings yielded no significant effects.

\section{Compliance Behavior}

Every participant pass salt and pepper when asked. That is, 20 out 20 people in each of the four sex/nose conditions comply.

\section{Response Time for Compliance}

Data (see Table 1) were treated with a $2 \times 2 \times 2 \times 2$ (Sex of Recipient $\times$ Nose Length of Requester $\times$ Substance $\times$ Substance Order) mixed model ANOVA with repeated measures on substance. Because order was 
not significant and did not interact significantly with any other variables, the datas were collapsed over it and a $2 \times 2 \times 2$ (Sex of Recipient $\times$ Nose Length of Requester $\times$ Substance) mixed ANOVA was conducted. The following effects were significant: sex of recipient, $F(1,76)=74.32, p<0.001$, nose length of requester, $F(1$, $76)=235.84, p<0.001$, sex of recipient $\times$ nose length of requester, $F(1,76)=21.39, p=0.007$, and substance, $F(1,76)=9.48, p=0.002$. For the three significant main effects, response times were slower for male recipient than for female recipient, for long nose requester than for short nose requester, and for pepper than for salt (see Table 1). Table 1 also shows that the two-way interaction between sex of recipient and nose length of requester occurred because the effect of nose length (slower for long) was greater for male requester than for female requester. That is, in the data, response times were always longer for long nose than for short nose, but this difference was greater when male requested than when female requested.

Table 1

Mean Response Times (sec) in Each Condition

\begin{tabular}{|c|c|c|c|c|c|c|}
\hline \multirow[b]{2}{*}{ Sender } & \multirow[b]{2}{*}{ Nose } & \multirow[b]{2}{*}{$n$} & \multicolumn{2}{|c|}{ Salt } & \multicolumn{2}{|c|}{ Pepper } \\
\hline & & & $M$ & $S D$ & $M$ & $S D$ \\
\hline \multicolumn{7}{|l|}{ Male } \\
\hline & Long & 20 & 5.05 & 1.22 & 5.08 & 1.17 \\
\hline & Normal & 20 & 2.01 & 0.54 & 2.36 & 0.33 \\
\hline \multicolumn{7}{|l|}{ Female } \\
\hline & Long & 20 & 3.03 & 0.44 & 3.27 & 0.48 \\
\hline & Normal & 20 & 1.53 & 0.42 & 1.69 & 0.35 \\
\hline
\end{tabular}

\section{Discussion}

Despite suggestions for future research on salt passage many years ago (Pacanowsky, 1978; Pencil, 1976), it was only recently (Minér, 2015) that the question was reconsidered. Consistent with previous results, expected results show that participants respond positively to request to pass salt. In addition, and as Minér (2015) surmmized, they also respond positively to request to pass pepper. Indeed, and also as suggested by Minér (2015), there is a perfect rate of compliance. That is, every sender pass salt and pepper when asked. This is unusual because earlier compliance rates were lower (Pacanowsky, 1978; Pencil, 1976). Most of that research was conducted in the 1960s and 1970s in the U.S.A. whereas the recent work is mostly in Canada but also in la France. Notably, Pacanowski (1976) reported that compliance is higher in Canada than in some other countries, although U.S.A. Nevertheless, one critical factor here might be agreeableness, because Canadians have a reputation for being "nice" (Weiner, 2015). Future research might focus on this variable going forward.

Although "rates" of compliance do not vary across conditions, "time" to fulfil request was related in the data to all three factors. In particular, and again as Minér (2015) indicated, response time was slower for pepper passage than for salt passage. As Minér observes, perhaps it is less usual to shake pepper over peanuts and chips than it is shake salt. Participants may have taken longer to respond because they were surprised. However, this effect might not occur in every country. For example, in India, where pepper originated (retrieved from http:// thehistoryvault.co.uk/salt-pepper/), people may shake it on many foods, and perhaps would not see it as unusual to shake it on their snack foods. This is good question for further cross-cultural investigation going forward.

Unlike Minér's (2015) proposal, in which time to comply was faster for requesters of opposite sex, which seems consistent with attractiveness theory, present female participants respond faster to "female" requester, 
which seems more consistent with similarity theory. Although Minér suggested that faster compliance to opposite sex was due to the attractiveness (wanting to please attractive person), present slower compliance to opposite sex might also be due to attractiveness because the female participants looked longer at the male requesters, causing them to delay responding. Consistent with this reasoning, in their casual anecdotal observations the experimenters can observe a tendency to gaze more at male requester.

However, the most interesting (and novel) finding here was that responding was "slower" when request (whether for salt or for pepper) was made by person (male or female) with "long" nose than by person with short nose. This result was expected because faces with long noses are less attractive than faces with short noses (Beaudouin \& Tiberghien, 2004; McKelvie, 1993) and compliance is negatively related to attractiveness (Debevec, Madden, \& Kernan, 1986). This result therefore provides further support for the attractiveness theory. However, effect of nose length was exaggerated when male made request. Other casual observations may point to a possible explanation. The experimenters noticed that when female participants were paired with another female who had long nose, they may rarely look at other person and appear embarrassed. However, when person sitting opposite was male with long nose, they may sneak more glances at him (albeit surreptitiously), and seem to be suppressing the laughter with noticeable wetness on her cheeks, but not upset tears. Directing attention to the emotion-control problem of suppressing visible signs of mirth in presence of a male face with a long nose may interfere with female participants' processing of request. In future research going forward participants could be given a post experimental questionnaire to record their subjective reactions.

All participants in the present experiment are women. This raises the question of whether the results would generalize to men. In particular, would the present exaggerated effect of nose length with female participants and male requester also occur with male participants and female requester? That is, would men be distracted by mirth in the presence of a woman with long nose?

It was speculated that the combination of pepper with long nose would create a condition with special consequences. However, this did not occur in the data. Even though pepper can make a person sneeze, a perception that may be exaggerated by presence of long nose, the slowing effect of pepper and slowing effect of nose length are independent. There is no evidence that the pepper/long nose combination was particularly distracting, resulting in slower compliance.

One strength of present experiment is that nose lengths of the participants themselves do not vary among the four conditions and are clearly in normal range. In particular, no participant has nose that even approaches the length of long one displayed here. It might be interesting to find participants with naturally longer noses and examine if their behavior differed from people with normal ones. For example, a person who had long nose might feel kinship with another person who also had long nose, causing them to pass salt or pepper more quickly. Sex might also play a role in this effect. The feeling of long nose kinship might vary for male and female participants faced with male and female requesters.

Returning to theoretical issues, similarity theory (Ajzen, 1974) suggests that people would respond faster to others who are more similar to themselves. Applied to nose length, this implies that participants respond faster to people with "similar" noses. However, attractiveness theory (Kulik \& Harackiewicz, 1979) suggests that people would respond faster to people considered to be attractive. That is, participants might respond faster to people with "normal" noses. The two theoretical alternatives should be further examined in future going forward with male and female participants who have long noses or normal noses. In addition, although the speculated exaggerated slowing effect of pepper with long nose (which might be a distractor via association 
with sneezing) did not occur in present experiment with female participants and a male or female requester, it might appear with male participants or with people of same sex.

\section{Conclusion}

In datas here, female participants comply with request to pass salt or pepper. However, they respond more slowly to pepper than to salt and person with long nose than to person with short nose, particularly with male requester. The experiment should be conducted and replicated with male participants and extended to include participants with long noses or normal noses and to other cultures, particularly in India.

\section{References}

Ajzen, I. (1974). Effects of information on interpersonal attraction: Similarity versus affective value. Journal of Personality and Social Psychology, 29, 374-380. http://dx.doi.org/10.1037/h0036002

Baudouin, J. V., \& Tiberghien, G. (2004). Symmetry, averageness, and feature size in the facial attractiveness of women. Acta Psychologia, 117, 313-332.

Debevec, K., Madden, T. J., \& Kernan, D. B. (1986). Physical attractiveness, message evaluation, and compliance. Psychological Reports, 58, 503-508.

Kulik, J. A., \& Harackiewicz, J. (1979). Opposite-sex interpersonal attraction as a function of the sex roles of the perceiver and the perceived. Sex Roles, 5, 443-452.

McKelvie, S. J. (1993). Effects of feature variations on attributions for schematic faces. Psychological Reports, 73, 275-288.

Minér, P. (2015). Sex as factor in salt and pepper passage: Updating the research. International Journal of Research and Review, 2(8), 487-491.

Pacanowsky, M. (1978). Salt passage research: The state of the art. Change, 10(8), 41-43. Retrieved from http://www.tandfonline.com/toc/vchn20/10/8\#.VZr707XLp2A

Pencil, M. (1976). Salt passage research: The state of the art: An update. Journal of Communication, 26(4), 31-36. Retrieved from http://onlinelibrary.wiley.com/doi/10.1111/jcom.1976.26.issue-4/issuetoc

Seriously Science (April 30, 2014). What the shape of your nose says about your quality as a mate. Retrieved from http://blogs.discovermagazine.com/seriouslyscience/2014/04/30/people-attractive-noses-evolutionarily-fit/\#.VcINHbWPvSg

Weiner, E. (March 19, 2015). Can Canada teach the rest of us to be nicer? Retrieved from http://www.bbc.com/travel/story/20150311-can-canada-teach-the-rest-of-us-to-be-nicer 